\title{
INCREMENTAL IMPROVEMENT OF COURSE OUTCOMES THROUGH INTERIM COURSE EVALUATIONS
}

\author{
Igor Ivkovic \\ Systems Design Engineering, University of Waterloo \\ igor.ivkovic@uwaterloo.ca
}

\begin{abstract}
With every new term, the method in which a course is delivered may need to be adjusted to reflect the changing needs of engineering students towards improving student engagement and learning. The information provided through standard end-of-the-term course evaluations is made available after the term is finished, so the instructors are unable to apply the feedback to the cohort that actually provided it. In this paper, we propose a method for incremental improvement of outcomes in engineering courses through the use of short, customizable, interim course evaluations that are coupled with short, in-class reflection sessions. The questions on the evaluations are related to the questions used on standard course evaluations, so that there is congruence between formative and summative instruments of feedback. The proposed method was applied on more than one occasion to improve student engagement, decrease failure rates, and align the learning objectives with students' interest.
\end{abstract}

Keywords: Engineering Education, Assessing Learning Experiences, Improving Course Outcomes, Incremental Improvement of Delivery Methods

\section{INTRODUCTION}

Each incoming cohort presents a unique set of teaching requirements, including but not limited to, what competency level should the instructors aim their explanations, what visual presentation method may work best for a specific course and specific cohort, and what specific curriculum topics students may find most engaging.

Unfortunately, the information provided through standard end-of-the-term course evaluations is made available after the term is finished, so the instructors are not given a chance to apply the feedback to the cohort that actually provided it. Also, the feedback provided through the standard evaluations may not apply to all cohorts, and the changes implemented in response to the feedback may neither be effective nor warranted in some cases. Instead, course instructors can administer interim course evaluations during the term to get immediate feedback that can be applied in a timely manner to improve student engagement and learning.
In this paper, we propose a method for incremental improvement of outcomes in engineering courses specifically, student engagement and understanding of course content - through the use of short, customizable, interim course evaluations that are coupled with short, inclass reflection sessions.

The rest of this paper is organized as follows: in Section 2, we describe how to design interim course evaluations, and explain how to address feedback provided. Finally, in Section 3, we present experiment results and conclusions.

\section{INCREMENTAL IMPROVEMENT OF COURSE OUTCOMES}

\subsection{Designing Interim Course Evaluations}

To enable repeated application of interim course evaluations, we propose to make the evaluations short and non-intrusive, and have them require a few minutes of students' time to complete in class within the immediate context of the learning environment.

The questions on the evaluations should be related to the questions used on standard course evaluations, so that there is congruence between formative and summative instruments of feedback.

As reference, a list of standard evaluation questions used within the Faculty of Engineering is provided below.

1. Rate your professor's presentation of lectures in terms of organization and clarity.

2. How would you rate your professor's response to questions?

3. Rate your professor's oral presentation in terms of audibility, articulation, and your ability to understand his / her English.

4. Rate your professor's visual presentation. Consider organization, legibility, and effective use of materials (blackboard, electronic media, etc). 
5. Describe the availability and approachability of your professor outside of class compared to other courses you've taken at university (Do not answer if you did not seek help).

6. At what level were the professor's explanations usually directed, in relation to your general level of understanding?

7. Were students encouraged by the professor to think and reason logically and objectively on their own about the subject matter?

8. What was your impression of your professor's attitude towards teaching the course?

9. Describe your professor-class relationship.

10. What was your overall appraisal of the quality of teaching in this course?

Based on observations in class, the instructor should select what aspect of the course delivery is in most need of improvement (e.g., organization and clarity of course material, quality of visual presentations, level of instructor's explanations), and formulate questions to collect specific feedback for incremental improvement. The instructor may also consider the impact of environment, value, and efficacy, and determine if one of these aspects requires improvement; for students to be motivated to learn, their learning environment should be supportive, they should see value in the material being taught, and they should feel confident about their ability to achieve set learning objectives [1]. The selected question should then be integrated into the short evaluation form; see Fig. 1 for a sample evaluation form.

\subsection{Addressing Provided Feedback}

After the evaluation is conducted, a short reflection session should be held during the following lecture, where students' feedback is presented as a summary, and where the instructor indicates how they intend to address the feedback. For instance, the instructor may choose to provide more examples during class, or more practice exercises outside of class.

As the term progresses, the instructor may run the evaluations again to check if the changes made were effective, and to determine if further adjustments are needed. Each application of interim evaluations should be followed by an in-class reflection session, to demonstrate to students that their feedback is valued and to illustrate continued improvement.

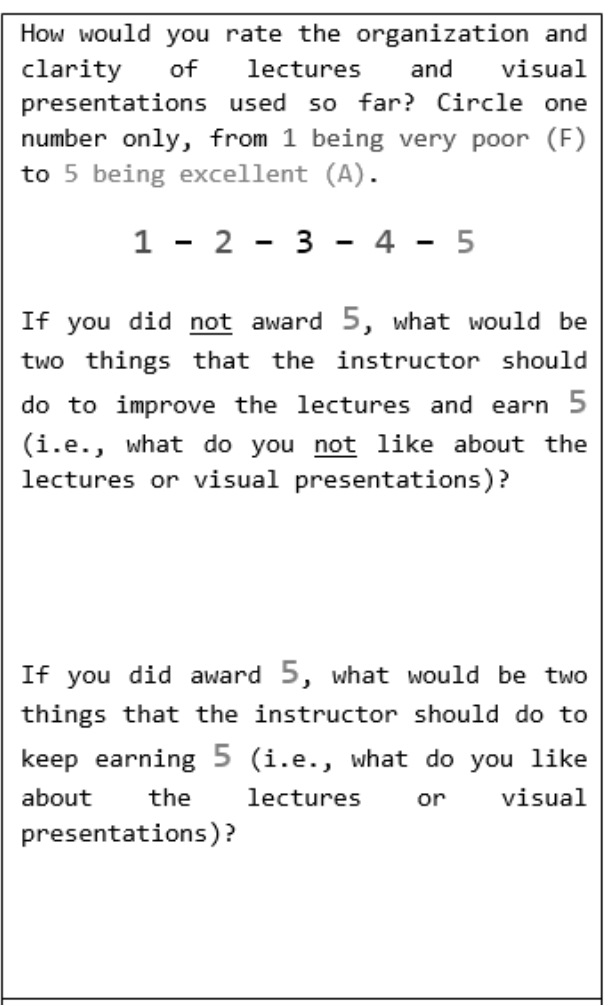

Figure 1. Sample Interim Evaluation Form

\section{RESULTS AND CONCLUSIONS}

The proposed method was first used in Spring 2015 to improve the outcomes of first-year courses in the Faculty of Engineering at the University of Waterloo. The method was successfully applied to improve student engagement, decrease failure rates, and align the learning objectives of the course with students' interests. The method was used again in Winter 2016 and Spring 2016 with demonstrated positive results towards improving the course outcomes.

The results obtained through standard end-of-the-term course evaluations showed continued improvement; for example, the most significant improvement was $10.8 \%$ for MTE 140 (Mechatronics Engineering) from Winter 2015 (80.2\%) to Spring 2015 (91.0\%) across ten categories on which the course delivery is evaluated in the Faculty of Engineering at the University of Waterloo.

\section{Acknowledgements}

We thank Dr. Gordon Stubley for providing the initial model based on which this approach was developed.

\section{References}

[1] Susan A Ambrose, Michael W Bridges, Michele DiPietro, Marsha Lovett, and Marie K Norman. How Learning Works: Seven Research-Based Principles for Smart Teaching. San Francisco, CA: Jossey-Bass, 2010. 